\title{
Maximization of Strategic Crops Production in Iraq with Fuzzy Goal Programming
}

\author{
Mohd Kamal Mohd Nawawi ${ }^{1,2, *}$, Ibrahim Zeghaiton Chaloob ${ }^{3}$, Jehan Saleh Ahmed ${ }^{4}$, \\ Razamin Ramli ${ }^{1}$, Suliadi Firdaus Sufahani ${ }^{5}$ \\ ${ }^{1}$ School of Quantitative Sciences, Universiti Utara Malaysia, Malaysia \\ ${ }^{2}$ Institute of Strategic Industrial Decision Modelling (ISIDM), Universiti Utara Malaysia, Malaysia \\ ${ }^{3}$ College of Applied Science, Fallujah University, Iraq \\ ${ }^{4}$ College of Women's Education, Al Iraqia University, Iraq \\ ${ }^{5}$ Faculty of Applied Sciences and Technology, Universiti Tun Hussein Onn Malaysia, Pagoh Campus, Malaysia
}

Received September 12, 2021; Revised December 27, 2021; Accepted January 16, 2022

\section{Cite This Paper in the following Citation Styles}

(a): [1] Mohd Kamal Mohd Nawawi, Ibrahim Zeghaiton Chaloob, Jehan Saleh Ahmed, Razamin Ramli, Suliadi Firdaus Sufahani , "Maximization of Strategic Crops Production in Iraq with Fuzzy Goal Programming," Universal Journal of Agricultural Research, Vol. 10, No. 1, pp. 20 - 26, 2022. DOI: 10.13189/ujar.2022.100102.

(b): Mohd Kamal Mohd Nawawi, Ibrahim Zeghaiton Chaloob, Jehan Saleh Ahmed, Razamin Ramli, Suliadi Firdaus Sufahani (2022). Maximization of Strategic Crops Production in Iraq with Fuzzy Goal Programming. Universal Journal of Agricultural Research, 10(1), 20 - 26. DOI: 10.13189/ujar.2022.100102.

Copyright $@ 2022$ by authors, all rights reserved. Authors agree that this article remains permanently open access under the terms of the Creative Commons Attribution License 4.0 International License

\begin{abstract}
The need to increase agricultural production has become a challenging task for most countries. Generally, many resource factors affect the deterioration of production level, such as low water level, desertification, soil salinity, low on capital, lack of equipment, the impact of export and import of crops, lack of fertilizers, pesticide, and the ineffective role of agricultural extension services which are significant in this sector. The main objective of this research is to develop fuzzy goal programming (GP) model to improve agricultural crop production, leading to increased agricultural benefits (more tons of produce per acre) based on the minimization of the main resources (water, fertilizer, and pesticide) to determine the weight in the objectives function subject to different constraints (land area, irrigation, labor, fertilizer, pesticide, equipment, and seed). Fuzzy GP (FGP) and GP were utilized to solve multi-objective decision-making (MODM) problems. From the results, this research has successfully presented a new alternative method that introduced multi-interval weights in solving a multi-objective FGP and GP model problem in a fuzzy manner, in the current uncertain decision-making environment for the agricultural sector. The significance of this research lies in the fact that some of the farming zones have resource limitations while others adversely impact their environment due to misuse of resources.
\end{abstract}

Keywords Agricultural Production Maximization,
Fuzzy Goal Programming, Goal Programming, Multi-interval Weights

\section{Introduction}

Agricultural improvement activities are normally associated with productivity due to changes in the agricultural process, such as the shift from the traditional human labor usage to advanced synthetic fertilizers and pesticides, selective breeding, and the mechanization of tools during the past century. However, agriculture has been related to many issues like water, land, biofuels, genetically modified organisms, farm subsidies, human resources, capital, tariffs, and import/export [1]-[3]. To solve these issues, multiple criteria have been considered in studies on mechanized agricultural activities, support for the organic movement, and sustainable agricultural development [4], [5]. Agricultural production is an important issue as the farming environment has an impact on rural improvement and agricultural productivity [6].

\subsection{Agriculture and Economic Development}

The role of farming in economic growth is an issue that 
still attracts the interest of scholars and particularly now when the whole growth approach is re-examined and evaluated. In agricultural development, investment is important to achieve the development goals of the millennium. Most of the leaders in the developing countries are committed to exerting effort and providing support for the development of agriculture and trade capacity-building in the agricultural sector [7]. This is because agricultural development contributes highly to the economic growth of developing countries. Moreover, the increasing agricultural production results in higher demands for processing equipment [8]. Hence, the agricultural production plans and their dependence on natural conditions have significant implications for the economy.

Some developing countries have no competitive edge in selling their agricultural products because of low land productivity and labor productivity. Following the liberalization of trade, domestic products could not compete with imported products that were of high quality and sold at a low price in countries such as Africa and Central Asia [9]. Consequently, farmers lost interest in investing in new methods to enhance product quality, leading to a decline in agricultural production. This causes a shortage in agricultural products and an increase in agricultural imports.

Agricultural planning has social and economic implications as it involves a complex interaction between economics and nature. The increasing population requires effective production to meet demand. However, the only way to do so is by increasing crop production for every unit area. This requires a careful and systematic crop planning process in relation to various resources such as land, water, labor, and capital and an investigation of other factors including irrigation methods, soil characteristics, cropping pattern, cropping intensity, topography, socio-economic conditions, and climate [10].

Agricultural planning issues cover many goals that are conflicting in improving crop production. Overall benefit, labor expenses, and water requirements among others are impossible to be simultaneously fulfilled, resulting in other goals to be forsaken to achieve an effective solution in the decision-making process [11].

\subsection{Agriculture in Iraq}

According to the statistics of the Central Statistical Organization (CSO), Ministry of Planning of Iraq [12] the land area of Iraq encapsulates four zones based on the division of topography. The total area of Iraq, which is $435,052 \mathrm{~km}^{2}$ can be categorized topographically as shown in Figure 1. The largest zone, the desert plateau covers $168,552 \mathrm{~km}^{2}(39 \%)$ of the area and is located in the west of Iraq with an altitude of about 100 to 1000 meters. Alluvial plain, a broad area of relatively flat landforms 132500 $\mathrm{km}^{2}$.or $30 \%$ of the Iraq area. The mountainous region is located in the north and northeast of Iraq and extends to Iraq's boundaries with Syria, Turkey, and Iran in the west, north, and east and forms $21 \%$ of Iraq's area, about 92000 $\mathrm{km}^{2}$. The last zone is the train region, a transitional region between lowlands in the south and mountains region, in the north and north-east, forms $42000 \mathrm{~km}^{2}$ with an altitude of 100-200 meters.

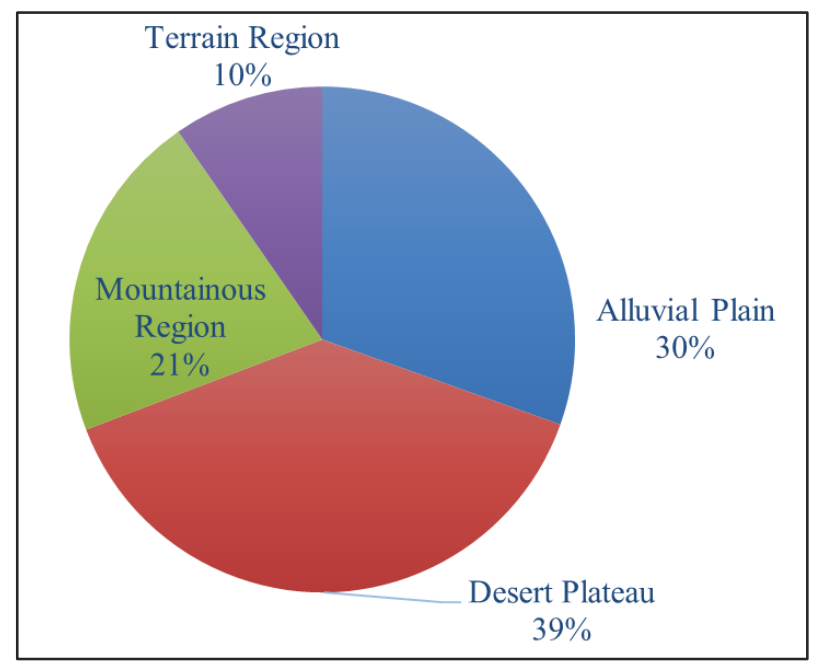

Figure 1. Percentage of Iraq land area topography

Iraq relies on its water resources on the water of the Tigris and Euphrates rivers and their tributaries. Around 85 percent of the irrigated agricultural sector in Iraq comes from water sources, making Iraq the pioneer among its Arab neighboring countries to be irrigated for agriculture. The Central Statistical Organization in the Ministry of Planning [13] reported the average water supply from these rivers and tributaries from 1990 until 2009 was 60.41 billion $\mathrm{m}^{3}$. However, during the years 2009-2010, there is a low water supply of only 32.11 billion $\mathrm{m}^{3}$ [13].

Iraq consists of 18 governorates from the north to the south. Iraq, which is strategically located in the Middle East region, is bordered by Iran to the east, Turkey to the north, Syria to the northwest, Jordan to the west, Saudi Arabia to the south and southwest, and the Arabian Gulf and Kuwait to the southeast and has two big rivers stream in the Iraqi lands, Tigris and Euphrates [14].

Agricultural production contributes modestly to Iraq's economy which constitutes around 3.6 percent of Gross Domestic Production (GDP) [1]. A mere 4 to 5 million hectares of Iraqi land is being cultivated in the arable land located in the north and northeast region of the country. Agricultural lands occupy about $20 \%$ of the total land surface in Iraq. About half of them are located in the North-Eastern plains and mountain valleys with sufficient rainfalls. Due to scarce rainfalls, the rivers supply water to irrigate fields with crops wheat and barley in winter and rice, corn, dates, cotton, vegetables, and fruits in summer [15]. In this particular area, summer and winter crops are primarily cultivated in the valleys of the Tigris and Euphrates rivers, the state controls cultivable land. 
With the land reforms in 1958, the sector's contribution to the GDP crops has gradually dropped [16], [17]. The two years following the reform were marked by a drought that drastically reduced production [18]. Agriculture's contribution to GDP was $22 \%$ in 1953 , but it was reduced to $13 \%$ in 2001 . Following that, due to a fall in oil earnings and the introduction of a policy of price control (prices are set in advance) for the main agricultural goods, its contribution climbed to 37.2 percent in the 1990s. Its contribution dropped to 8.4 percent in $2003,4.56$ percent in 2011, and 2 percent in 2018 [17]. This is compounded by the need for more pesticides, fertilizers, and machinery along with the presence of imported agricultural products under the UN food-for-oil program enabling the sale of a certain amount of oil in lieu of basic food and medicine. Iraqi farmers also faced the adverse effects of drought and a century of wars [13].

\subsection{Research Motivation}

Many factors affect the deterioration of production level, for example, low water level, desertification, salinity in the soil, labor, obsolete mechanization, effects of export and import of crops, lack of fertilizer, and pesticides. Even the GDP percentage of Iraq is not as high as other non-oil producers Arab and agriculture highly dependent African countries [19], the Iraq Ministry of Planning attempted some ways to achieve perfect agricultural productions, such as by maximizing the production crops, maximizing the profit, and exploiting water irrigation, labor, fertilizer, and pesticides [13]. However, these strategies can still be improved.

Extensive literature indicates that there is an absence of comprehensive agricultural planning and optimizing of available resources [13], [20]. Therefore, there is a need to have a proper scientific plan to optimize the usage of lands, taking into account the direct and the indirect diversity of restrictions that can assist in optimizing the availability of resources while observing the flexibility of rotations of crops, especially the strategic crops.

Hence, this motivates us to improve the problem scenario by including several other constraints, such as yearly food crops constraints, industrial crops constraints, oil crops constraints, water constraints, and fertilizer constraints. Furthermore, our research also considers crops that can tolerate the salinity of lands. But, there is a gap in identifying what is the best and suitable approach to tackling the problem in a real situation of agricultural production, where there is a need to control the priority of different resources.

The objective of this paper is to compare the multi-interval weights FGP and GP models with the existing single-interval weights models. Prior to that, we identified the performance goals which are resources such as water, fertilizer, and pesticides on the environment in improving crops production in different geographical zones.
In order to develop the proposed mathematical model in maximizing crops production, the environment of agricultural production in Iraq was used as a case problem. There are 15 agricultural zones located in the Mesopotamian plains by the Tigris and Euphrates rivers. However, in this research, only five important zones were considered based on suggestions by the authority in the Ministry of Agriculture Iraq. These zones are also among the biggest of the 15 which cover most of the areas in Iraq.

The crops involved in the modeling of agricultural production are 20 out of 22 , which are wheat, barley, onion, potato, lettuce, carrot, tomato, mash, pepper, green bean, rice, string bean, garlic, squash, cucumber, millet, corn, sunflower, cotton and sesame seed plant. The other two; sugar beet and sugar cane were not considered due to the unavailability of data. These crops are also known as strategic crops since they are heavily consumed by the population.

All data related to this development of strategic crop production model were taken from the Manual of Agricultural Statistical Indicators of Iraq for 2002 and 2010. The data provided all information used in the planning of agriculture for these two years.

The modeling of strategic crops production problems in this research involved nine types of constraints. These constraints are related to land, water, fertilizer, pesticides, labor, equipment, seeds, demand, and individual crops production.

\section{Methodology}

To achieve the main goal of this research, the FGP model is deemed necessary to be developed with an embedded new multi-interval weight. The proposed FGP model is to solve a multi-objective problem using goal programming (GP) and fuzzy goal concepts. GP has been recognized as a fundamental mathematical programming method for handling many optimization issues [21]. This research focuses on model developments, where two types of quantitative data are utilized. They are primary and secondary data.

The quantitative data was the primary data collected from decision-makers and farmers in the agricultural sector. In addition, some decision-makers with expertise in the areas of field crops, food industry, plant protection, biological techniques, garden design, agricultural engineering, biological chemistry, and agricultural economy were also approached. Some of the quantitative data is quantifiable for quantitative analysis. On the other hand, the secondary quantitative data was obtained from reports in the agricultural sector.

Interval programming is one approach to tackling uncertainty in mathematical programming models. It has been used to tackle specific issues in multi-objective linear programming. In the case of uncertainty in weights, the 
interval weights, also known as the single interval weight (SIW) method, are a popular tool for tackling such uncertain weight structures [22]. Then the sum of unwanted deviations associated with their respective goals is considered to achieve the goal values within the specified range.

The FGP model was then developed using the enhanced multi-interval weights (MIW) method, which is used in the deviations of agricultural benefits as the variables in the FGP. For evaluation purposes, a GP was also developed embedding the new MIW, which the results were compared to that of the FGP. Experimentation and analyses were carried out to validate the two models. The combination of the two types of interval weights of the criteria, i.e., the single interval weights (SIW) and multi-interval weights (MIW) with the FGP and GP formed four models known as the SIWFGP, SIWGP, MIWFGP, and MIWGP models. Several comparison analyses were done among these four models. The details of the models and their characteristics were presented in Chaloob et al. [23].

\section{Results and Discussion}

Evaluation of the solutions for the FGP and GP models based on the proposed MIW method is presented to show how the novel MIW method achieves the most appropriate weights to represent the levels of importance in the crops production problem. The performance of the proposed MIWFGP, MIWGP, and the existing SIWFGP and SIWGP models are analyzed using several sets of data available for the years 2002 and 2010 .

Furthermore, the implementation of these proposed models with weights derived from the existing SIW method is addressed to compare the solutions of proposed models.

\subsection{Evaluation of the MIWFGP and MIWGP for 2002 Data}

In order to evaluate the performance of the proposed MIW method, this research used the existing SIW method as a comparison. This comparison supports our proposed models under different methods for the preference of decision-makers to improve crops production problems.

Table 1. Comparison of Goal Values Obtained under MIWFGP and SIWFGP Models for 2002 Data

\begin{tabular}{|c|c|c|}
\hline Goals & MIWFGP & SIWFGP \\
\hline $\begin{array}{c}\text { Agricultural benefit } \\
Z_{1}(\mathrm{ID})\end{array}$ & $7.507 \times 10^{13}$ & $7.507 \times 10^{13}$ \\
\hline $\begin{array}{c}\text { Water irrigation } \\
Z_{2}\left(\mathrm{~m}^{3}\right)\end{array}$ & $4.796 \times 10^{10}$ & $4.799 \times 10^{10}$ \\
\hline $\begin{array}{c}\text { Fertilizer requirements } \\
Z_{3} \text { (ton) }\end{array}$ & $4.726 \times 10^{8}$ & $4.732 \times 10^{8}$ \\
\hline $\begin{array}{c}\text { Pesticides requirements } \\
Z_{4}(\mathrm{~kg})\end{array}$ & $1.398 \times 10^{7}$ & $1.405 \times 10^{7}$ \\
\hline
\end{tabular}

The existing SIW method with FGP and GP models is known as SIWFGP and SIWGP models. These two models are derived and applied to the same 2002 data to obtain crops production results. The goals values for 2002 data with MIWFGP and SIWFGP models based on the interval weights results are shown in Table 1.

From Table 1, it can be observed that the agricultural benefit goal, $Z_{1}$ under each of the SIWFGP and MIWFGP models is the same value of $7.507 \times 10^{13}$ ID (Iraqi Dinar). However, the minimization goals which are the water irrigation goal, $Z_{2}$ decreased from $4.799 \times 10^{10} \mathrm{~m}^{3}$ under on SIWFGP model to $4.796 \times 10^{10} \mathrm{~m}^{3}$ under the MIWFGP model, the fertilizer requirements goal, $Z_{3}$ decreased from $4.732 \times 10^{8}$ tons under the SIWFGP to $4.726 \times 10^{8}$ ton under MIWFGP. In addition, the pesticides requirements goal, $Z_{4}$ decreased from $1.405 \times 10^{7} \mathrm{~kg}$ under the SIWFGP to $1.398 \times 10^{7} \mathrm{~kg}$ under the MIWFGP model. The results show that the minimization values for goals $Z_{2}, Z_{3}$, and $Z_{4}$ are achieved through the proposed MIWFGP model, except for the $Z_{l}$. The monetary benefit seems to have the same value but with good consideration of water, fertilizer, and pesticide control.

Similarly, the goals values for 2002 data with MIWGP and SIWGP models based on the interval weights results are shown in Table 2.

Table 2. Comparison of Goal Values Obtained under MIWGP and SIWGP Models for 2002 Data

\begin{tabular}{|c|c|c|}
\hline Goals & MIWGP & SIWGP \\
\hline $\begin{array}{c}\text { Agricultural benefit } \\
Z_{l}(\mathrm{ID})\end{array}$ & $9.272 \times 10^{13}$ & $9.277 \times 10^{13}$ \\
\hline $\begin{array}{c}\text { Water irrigation } \\
Z_{2}\left(\mathrm{~m}^{3}\right)\end{array}$ & $5.202 \times 10^{10}$ & $5.507 \times 10^{10}$ \\
\hline $\begin{array}{c}\text { Fertilizer requirements } \\
Z_{3} \text { (ton) }\end{array}$ & $4.943 \times 10^{8}$ & $5.662 \times 10^{8}$ \\
\hline $\begin{array}{c}\text { Pesticides requirements } \\
Z_{4}(\mathrm{~kg})\end{array}$ & $1.473 \times 10^{7}$ & $1.932 \times 10^{7}$ \\
\hline
\end{tabular}

From Table 2, it can be observed that the agricultural benefit goal, $Z_{l}$ under MIWGP is $9.272 \times 10^{13} \mathrm{ID}$, while under SIWGP is $9.277 \times 10^{13}$ ID. That means the existing SIWGP method gives the value of the goal, $Z_{l}$ more than that of the proposed MIWGP method. However, the minimization goals which are the water irrigation goal, $Z_{2}$ decreased from $5.507 \times 10^{10} \mathrm{~m}^{3}$ based on the SIWGP model to $5.202 \times 10^{10} \mathrm{~m}^{3}$ with the MIWGP model. Furthermore, the fertilizer requirements goal, $Z_{3}$ decreased from $5.662 \times 10^{8}$ tons based on the SIWGP to $4.943 \times 10^{8}$ tons under the MIWGP. In addition, pesticides requirements goal, $Z_{4}$ is decreased from $1.932 \times 10^{7} \mathrm{~kg}$ under the SIWGP to $1.473 \times 10^{7} \mathrm{~kg}$ under the MIWGP models. The results show that the minimization values for goals $Z_{2}, Z_{3}$, and $Z_{4}$ are achieved through the proposed MIWGP model, except for the $Z_{l}$. The monetary benefit seems to decrease but with good consideration of water, fertilizer, and pesticide control. 


\subsection{Evaluation of the MIWFGP and MIWGP for 2010 Data}

The process of evaluating the proposed MIWFGP and MIWGP models for 2010 data is the same as was done with 2002 data. Similarly, the goal values for 2010 data with MIWFGP and SIWFGP models based on the interval weights results are shown in Table 3.

Table 3. Comparison of Goal Values Obtained under MIWFGP and SIWFGP Models for 2010 Data

\begin{tabular}{|c|c|c|}
\hline Goals & MIWFGP & SIWFGP \\
\hline $\begin{array}{c}\text { Agricultural benefit } \\
Z_{I}(\mathrm{ID})\end{array}$ & $9.75 \times 10^{13}$ & $7.86 \times 10^{13}$ \\
\hline $\begin{array}{c}\text { Water irrigation } \\
Z_{2}\left(\mathrm{~m}^{3}\right)\end{array}$ & $6.81 \times 10^{10}$ & $6.86 \times 10^{10}$ \\
\hline $\begin{array}{c}\text { Fertilizer requirements } \\
Z_{3} \text { (ton) }\end{array}$ & $1.13 \times 10^{9}$ & $1.20 \times 10^{9}$ \\
\hline $\begin{array}{c}\text { Pesticides requirements } \\
Z_{4}(\mathrm{~kg})\end{array}$ & $1.83 \times 10^{7}$ & $1.52 \times 10^{7}$ \\
\hline
\end{tabular}

From Table 3, it can be observed that the agricultural benefit goal, $Z_{l}$ under MIWFGP is $9.75 \times 10^{13} \mathrm{ID}$, while under SIWFGP is $7.86 \times 10^{13} \mathrm{ID}$. That means the proposed MIWFGP gives the value of the goal, $Z_{l}$ more than that of the existing SIWFGP method. However, the minimization goals which are the water irrigation goal, $Z_{2}$ decreased from $6.86 \times 10^{10} \mathrm{~m}^{3}$ under on SIWFGP model to $6.81 \times 10^{10} \mathrm{~m}^{3}$ under the MIWFGP model, the fertilizer requirements goal, $Z_{3}$ decreased from $1.20 \times 10^{9}$ ton under the SIWFGP to $1.13 \times 10^{9}$ ton under MIWFGP. In addition, the pesticides requirements goal, $Z_{4}$ increased from $1.52 \times 10^{7} \mathrm{~kg}$ under the SIWFGP to $1.83 \times 10^{7} \mathrm{~kg}$ under the MIWFGP model. The results show that the value for goal, $Z_{1}$, and the minimization values for goals $Z_{2}$ and $Z_{3}$ are achieved through the proposed MIWFGP model, except for the $Z_{4}$. The pesticides requirements seem to increase but with good consideration of benefit, water, and fertilizer control.

Similarly, the goals values for 2010 data with MIWGP and SIWGP models based on the interval weights results are shown in Table 4.

From Table 4, it can be observed that the agricultural benefit goal, $Z_{l}$ under MIWGP is $1.65 \times 10^{14} \mathrm{ID}$, while under SIWGP is $1.93 \times 10^{14} \mathrm{ID}$. That means the existing SIWGP method gives the value of the goal, $Z_{l}$ more than that of the proposed MIWGP method. However, the minimization goals which are the water irrigation goal, $Z_{2}$ decreased from $2.01 \times 10^{11} \mathrm{~m}^{3}$ based on the SIWGP model to $1.53 \times 10^{11} \mathrm{~m}^{3}$ with the MIWGP model. Furthermore, the fertilizer requirements goal, $Z_{3}$ decreased from $1.43 \times 10^{9}$ tons based on the SIWGP to $1.20 \times 10^{9}$ tons under the MIWGP. In addition, the pesticides requirements goal, $Z_{4}$ is decreased from $3.17 \times 10^{7} \mathrm{~kg}$ under the SIWGP to $3.01 \mathrm{x}$ $10^{7} \mathrm{~kg}$ under the MIWGP models. The results show that the minimization values for goals $Z_{2}, Z_{3}$, and $Z_{4}$ are achieved through the proposed MIWGP model, except for the $Z_{l}$. The monetary benefit seems to decrease but with good consideration of water, fertilizer, and pesticide control.

Table 4. Comparison of Goal Values Obtained under MIWGP and SIWGP Models for 2010 Data

\begin{tabular}{|c|c|c|}
\hline Goals & MIWGP & SIWGP \\
\hline $\begin{array}{c}\text { Agricultural benefit } \\
Z_{I}(\mathrm{ID})\end{array}$ & $1.65 \times 10^{14}$ & $1.93 \times 10^{14}$ \\
\hline $\begin{array}{c}\text { Water irrigation } \\
Z_{2}\left(\mathrm{~m}^{3}\right)\end{array}$ & $1.53 \times 10^{11}$ & $2.01 \times 10^{11}$ \\
\hline $\begin{array}{c}\text { Fertilizer requirements } \\
Z_{3} \text { (ton) }\end{array}$ & $1.20 \times 10^{9}$ & $1.43 \times 10^{9}$ \\
\hline $\begin{array}{c}\text { Pesticides requirements } \\
Z_{4}(\mathrm{~kg})\end{array}$ & $3.01 \times 10^{7}$ & $3.17 \times 10^{7}$ \\
\hline
\end{tabular}

\subsection{Discussion}

The results for 2002 data show that the minimum values of goals $Z_{2}, Z_{3}$, and $Z_{4}$ are obtained through the proposed MIWFGP model, while the maximum value of $Z_{l}$ is from SIWGP. Meanwhile, for 2010 data, the minimum values of goals $Z_{2}$ and $Z_{3}$ are also obtained through the proposed MIWFGP model and the maximum value of $Z_{l}$ is also from SIWGP. The only difference is for $Z_{4}$, where SIWFGP is the best model. Table 5 shows the rank of best goals for both 2002 and 2010 data.

From Table 5, with the concepts and goals of sustainable development, the decision-makers should consider all the environmental goals as important and the achievement of these targets should also be taken into account. These results indicate that MIWFGP is superior to other models. However, if the main goal is to maximize the monetary benefit, then SIWGP is the best model to apply to Iraqi agriculture production.

Table 5. The Rank of Goal Values Obtained under All Models for 2002 and 2010 Data

\begin{tabular}{|c|c|c|c|c|c|c|c|c|}
\hline Goals & \multicolumn{4}{|c|}{ 2002 } & \multicolumn{5}{c|}{2010} \\
\hline & MIWFGP & SIWFGP & MIWGP & SIWGP & MIWFGP & SIWFGP & MIWGP & SIWGP \\
\hline $\begin{array}{c}\text { Agricultural benefit } \\
Z_{l}(\text { ID) }\end{array}$ & $3-4$ & $3-4$ & 2 & $\mathbf{1}$ & 3 & 4 & 2 & $\mathbf{1}$ \\
\hline $\begin{array}{c}\text { Water irrigation } \\
Z_{2}\left(\mathrm{~m}^{3}\right)\end{array}$ & $\mathbf{1}$ & 2 & 3 & 4 & $\mathbf{1}$ & 2 & 3 & 4 \\
\hline $\begin{array}{c}\text { Fertilizer requirements } \\
Z_{3} \text { (ton) }\end{array}$ & $\mathbf{1}$ & 2 & 3 & 4 & $\mathbf{1}$ & $2-3$ & $2-3$ & 4 \\
\hline $\begin{array}{c}\text { Pesticides requirements } \\
Z_{4}(\mathrm{~kg})\end{array}$ & $\mathbf{1}$ & 2 & 3 & 4 & 2 & $\mathbf{1}$ & 3 & 4 \\
\hline
\end{tabular}




\section{Conclusions}

Analysis and evaluation of the proposed MIWFGP and MIWGP models to solve real problems in the agricultural sector in Iraq were done. We summarize that the proposed models combine the attractive features of the MIW with FGP and GP. These models with interval weight aim to optimize the goals simultaneously in agricultural production problems. In the proposed models, we used two data sets from the years 2002 and 2010. The comparisons support the effectiveness of our proposed models to solve the agriculture production problem in Iraq.

The results indicate that the MIWFGP model is superior to the MIWGP model since the MIWFGP was constructed as a model with the integrated management of various important resources. We conclude that the MIWFGP model can better improve agriculture production if compared to the SIW model. The preceding results show that the proposed MIW method is better in achieving the objective values than the existing method SIW under both the MIWGP and the MIWFGP.

The results of the proposed MIWFGP and MIWGP models can be applied to the agriculture crop production improvement to support their decision-making processes in allocating different land use to achieve specific objectives in this sector. The results of the proposed MIWFGP and MIWGP models suggested that the decision-makers focus on some of the crops that have high values in maximizing agricultural crop production.

\section{Acknowledgment}

This research is funded by Universiti Utara Malaysia under Postgraduate Incentive Research Grant Scheme with S/O Code 15504.

\section{Conflict of Interest}

The authors declare that they have no conflict of interest.

\section{REFERENCES}

[1] P. Lucani, "Iraq: Agriculture sector note," Rome, Italy, 2012. [Online]. Available: http://www.fao.org/docrep/017/ i2877e/i2877e.pdf.

[2] E. W. Chirwa, I. Kumwenda, C. Jumbe, P. Chilonda, and I. Minde, "Agricultural growth and poverty reduction in Malawi: Past performance and recent trends," ReSAKSS-SA Work. Pap., vol. 8, 2008.

[3] A. Gelli et al., "Value chains to improve diets: Diagnostics to support intervention design in Malawi," Glob. Food Sec., vol. 25, p. 100321, Jun. 2020, doi: 10.1016/J.GFS.2019.09. 006.
[4] L. Tang, K. Hayashi, K. Kohyama, and A. Leon, "Reconciling life cycle environmental impacts with ecosystem services: A management perspective on agricultural land use," Sustain., vol. 10, no. 3, 2018, doi: $10.3390 /$ su10030630.

[5] S. Bellon and S. Penvern, Organic farming, prototype for sustainable agricultures: Prototype for sustainable agricultures, vol. 9789400779. 2014.

[6] C. Srinivasarao, R. Lal, S. Kundu, and P. B. Thakur, Conservation agriculture and soil carbon sequestration. 2015.

[7] I. Adelman and C. T. Morris, "Economic development and the distribution of income," in The Gap Between Rich and Poor, Routledge, 2019, pp. 151-155.

[8] C. Musvoto, K. Nortje, B. De Wet, B. K. Mahumani, and A. Nahman, "Imperatives for an agricultural green economy in South Africa," S. Afr. J. Sci., vol. 111, no. 1-2, 2015, doi: 10.17159/sajs.2015/20140026.

[9] C. P. Timmer, "Food Security, Structural Transformation, Markets and Government Policy," Asia $\backslash \&$ Pacific Policy Stud., vol. 4, no. 1, pp. 4-19, 2017, doi: https://doi.org/10. 1002/app5.161.

[10] M. Bhatia and A. Rana, "A mathematical approach to optimize crop allocation - A linear programming model," Int. J. Des. Nat. Ecodynamics, vol. 15, no. 2, pp. 245-252, 2020, doi: 10.18280/ijdne.150215.

[11] M. Nematollahi and A. Tajbakhsh, "Past, present, and prospective themes of sustainable agricultural supply chains: A content analysis," J. Clean. Prod., vol. 271, p. 122201, Oct. 2020, doi: 10.1016/J.JCLEPRO.2020.122201.

[12] Central Statistical Organization (CSO) Ministry of Planning Iraq, "Annual statistical abstract," Baghdad, 2020. [Online]. Available: http://cosit.gov.iq/ar/2018-2019.

[13] Ministry of Planning, "Agricultural statistical Atlas roadmap for agricultural development (green economy)," Baghdad, 2011.

[14] National Investment Commission, "Investment Map of Iraq 2020-2021," Baghdad, 2020. [Online]. Available: https://investpromo.gov.iq/wp-content/uploads/2021/02/in vestment-Map-2021-En.pdf.

[15] O. Tokareva, O. Pasko, A. Alshaibi, and M. Mochalov, "Monitoring-based analysis of agriculture in Iraq," in IOP Conference Series: Earth and Environmental Science, 2016, vol. 43, no. 1, doi: 10.1088/1755-1315/43/1/012035.

[16] N. Al-Ansari, S. A. Abed, and S. H. Ewaid, "Agriculture in Iraq," J. Earth Sci. Geotech. Eng., vol. 11, no. 2, pp. 223 241, 2021.

[17] H. Abbas Drebee and N. Azam Abdul-Razak, "The Impact of Corruption on Agriculture Sector in Iraq: Econometrics Approach," in IOP Conference Series: Earth and Environmental Science, 2020, vol. 553, no. 1, doi: $10.1088 / 1755-1315 / 553 / 1 / 012019$.

[18] Y. Al Rashid, "The Role of the Military Governments \& the Baath Regime in the Land Reforms and Co-operative Development of Iraq's Agriculture. Lessons for those attempting political and economic reform in the emerging Iraq," Int. J. Co-op. Manag., vol. 2, no. 1, 2005. 
[19] D. Bamwesigye, A. Doli, K. J. Adamu, and S. K. Mansaray, "A review of the political economy of agriculture in Uganda: Women, property rights, and other challenges," Univers. J. Agric. Res., vol. 8, no. 1, pp. 1-10, 2020, doi: 10.13189/ujar.2020.080101.

[20] S. Beer, The United States' Program for Agriculture in Post-Invasion Iraq. Lulu Press, 2016.

[21] S. Rabee, R. Hamed, R. Kassem, and M. Rashwaan, "A goal programming approach for multivariate calibration weights estimation in stratified random sampling," Math. Stat., vol. 9, no. 3, pp. 326-334, 2021, doi: 10.13189/ms.2021.090314.
[22] S. Sen and B. B. Pal, "Interval Goal Programming Approach to Multiobjective Fuzzy Goal Programming Problem with Interval Weights," Procedia Technol., vol. 10, pp. 587-595, 2013, doi: 10.1016/j.protcy.2013.12.399.

[23] I. Z. Chaloob, R. Ramli, and M. K. M. Nawawi, "A new multi-interval weights approach in fuzzy goal programming for a multi-criteria problem," Int. J. Math. Oper. Res., vol. 9, no. 2, pp. 214-229, Jan. 2016, doi: 10.1504/IJMOR.2016.0 77998 . 